\title{
Validation of annual skeletal marks in green sea turtles Chelonia mydas using tetracycline labeling
}

\author{
Melissa L. Snover ${ }^{1,3}$, Aleta A. Hohn², Lisa R. Goshe ${ }^{2}$, George H. Balazs ${ }^{1}$ \\ ${ }^{1}$ National Oceanographic and Atmospheric Administration (NOAA), National Marine Fisheries Service, \\ Pacific Islands Fisheries Science Center, 2570 Dole Street, Honolulu, Hawaii 96822, USA \\ ${ }^{2}$ NOAA, National Marine Fisheries Service, Southeast Fisheries Science Center, NOAA-Beaufort Lab, \\ 101 Pivers Island Road, Beaufort, North Carolina 28516, USA \\ ${ }^{3}$ Present address: Denali National Park and Preserve, PO Box 9, Denali Park, Alaska 99755, USA
}

\begin{abstract}
The technique of skeletochronology has been widely applied to age and growth studies of most species of sea turtles, although direct validation of annual growth marks has only been demonstrated for loggerheads Caretta caretta and Kemp's ridleys Lepidochelys kempii. In this study we present validation of annual growth mark deposition in green sea turtles Chelonia mydas. Fourteen green sea turtles, previously captured in nearshore waters in the main Hawaiian Islands and injected with oxytetracycline (OTC), were recovered stranded, and the humeri were prepared for skeletochronological analysis. Each sea turtle had received a single dose of $25 \mathrm{mg} \mathrm{kg}^{-1}$ OTC, with half injected into each pectoral muscle. Seven of these sea turtles either were not at large long enough or did not grow enough for either the OTC mark to be discernable in bone cross-sections or for a growth mark to have been deposited after the OTC mark. Based on the hypothesis of one mark per year, the expected number of growth marks was visible exterior to the OTC mark in the humeri of the 7 remaining sea turtles, providing strong validation that growth marks are annual. These results support the use of skeletochronology for age and growth rate estimates in green sea turtles and the need for validation to ensure accurate interpretation of growth marks.
\end{abstract}

KEY WORDS: Fluorescent marks $\cdot$ Skeletochronology $\cdot$ Age $\cdot$ Growth marks

\section{INTRODUCTION}

Skeletochronology is based on the concept that bone growth is cyclic and that these cycles can be identified by histological features in the bone. The 2 most common features in histological preparations of bone cross-sections are (1) thin lines that appear darker than the surrounding tissue, termed lines of arrested growth (LAG), and (2) broad zones that stain homogeneously light (Castanet et al. 1993). LAGs and zones alternate and together a broad zone followed by a LAG comprises one skeletal growth mark (Castanet et al. 1993), with the most recent growth marks being deposited at the outer edge of bone cross-sections. The technique of skeletochronology has been widely applied to sea turtles in general (Zug et al.
1986, Snover \& Hohn 2004) and green sea turtles Chelonia mydas specifically (Bjorndal et al. 1998, Zug \& Glor 1998, Zug et al. 2002, Goshe et al. 2010). Several studies have validated that skeletal growth marks deposited in the humeri of loggerhead Caretta caretta and Kemp's ridley Lepidochelys kempii sea turtles are annual (Klinger \& Musick 1992, Coles et al. 2001, Snover \& Hohn 2004). No studies have provided direct evidence of annual growth marks in green sea turtles; however, Goshe et al. (2010) provided indirect evidence that growth marks are annual for North Atlantic green sea turtles. Another study attempted to validate the technique but was unable to identify growth marks in green sea turtles captured in the southern Bahamas (Bjorndal et al. 1998). Furthermore, they called into question the application of skele- 
tochronology to sea turtles that inhabit tropical waters, suggesting that they do not deposit annual growth marks. However, growth marks have been clearly observed in green sea turtles inhabiting south Florida and Hawaii, USA (Zug \& Glor 1998, Zug et al. 2002), and all 3 regions, the Bahamas, south Florida and Hawaii, fall into the Köppen-Geiger climate classification of equatorial (Kottek et al. 2006).

The use of fluorescent markers such as oxytetracycline (OTC) has been demonstrated to be a reliable method for the validation of skeletochronology in sea turtles (Frazier 1985, Klinger \& Musick 1992). When bone growth occurs following treatment with an adequate dose of OTC, OTC is incorporated into mineralizing bone (Milch 1958), making it possible to determine the frequency of LAG deposition by comparing the number of LAGs exterior to the OTC mark with the number of years the sea turtle was at large. In captive experiments with farm-reared green sea turtles, Frazier (1985) found that doses ranging from 5 to $28 \mathrm{mg}$ $\mathrm{kg}^{-1}$ resulted in fluorescent lines in the peripheral bone tissue, with higher doses resulting in greater fluorescence. In a study of wild loggerhead sea turtles, Klinger \& Musick (1992) found fluorescing marks in 9 out of 14 bone biopsies taken from recaptured sea turtles that had been previously injected with OTC.

Two long-term sea turtle monitoring programs around the Hawaiian Islands contributed to the success of this project. The first program is a long-term ocean-capture tagging study of green sea turtles which provided the opportunity to mark a large number of sea turtles with OTC (Balazs \& Chaloupka 2004). The second is a comprehensive stranding program whereby the majority of sea turtles found sick, injured or dead around the Hawaiian Islands are recovered and brought in for treatment or necropsy (Chaloupka et al. 2008). This second program enabled the recovery and identification of previously captured and OTCtreated sea turtles that subsequently died, providing an opportunity to retain their humeri for study. In the present study, we examined those humeri, and present evidence that growth marks are deposited annually in Hawaiian green sea turtles.

\section{MATERIALS AND METHODS}

To date, 14 Hawaiian green sea turtles ranging from 44.5 to $85.5 \mathrm{~cm}$ straight carapace length (SCL) (mean \pm $\mathrm{SD}=62.9 \pm 10.8 \mathrm{~cm}$ ) that were previously injected with OTC have been recovered as either stranded dead, or alive and subsequently euthanized on the advice of a veterinarian, and the humeri prepared for skeletochronology analysis (Table 1). Eleven of the turtles in the present study were injected with OTC during mark-recapture studies (Balazs \& Chaloupka 2004; Table 1). The other 3 sea turtles were originally recovered as live strandings and injected with OTC prior to release. Each sea turtle received a single dose of $25 \mathrm{mg}$ $\mathrm{kg}^{-1}$ OTC (Liquamycin LA-200, Pfizer Animal Health),

Table 1. Chelonia mydas. Capture and recovery details for Hawaiian green sea turtles treated with oxytetracycline (OTC). For acquisition and recovery methods, the island where the sea turtle was found is listed. DS: dead stranding; LS-R: live stranding that was released; LS-Eu: live stranding that was euthanized; OC: ocean capture. Size is listed as straight carapace length measured from the nuchal notch to the posterior-most scute. Tumor score refers to the level of fibropapilloma tumors observed on the sea turtle at recovery (0: no tumors; 1 : mildly tumored; 2 : moderately tumored; 3 : severely tumored). Sex is recorded as male (M), female (F) or undetermined (U). When possible, sex was determined via examination of the gonads during necropsy

\begin{tabular}{|c|c|c|c|c|c|c|c|c|}
\hline ID & $\begin{array}{l}\text { OTC date } \\
\text { (mm/dd/yy) }\end{array}$ & $\begin{array}{l}\text { Acquisition } \\
\text { method }\end{array}$ & $\begin{array}{l}\text { Size at OTC } \\
(\mathrm{cm})\end{array}$ & $\begin{array}{l}\text { Recovery date } \\
\text { (mm/dd/yy) }\end{array}$ & $\begin{array}{l}\text { Recovery } \\
\text { method }\end{array}$ & $\begin{array}{c}\text { Size at } \\
\text { recovery }(\mathrm{cm})\end{array}$ & $\begin{array}{l}\text { Tumor } \\
\text { score }\end{array}$ & Sex \\
\hline CM-1 & $04 / 23 / 97$ & OC, Hawaii & 55.1 & 02/08/99 & DS, Hawaii & $58.5^{\mathrm{a}}$ & 0 & $\mathrm{U}$ \\
\hline CM-2 & $12 / 29 / 98$ & LS-R, Maui & 60.0 & 05/13/99 & DS, Oahu & 60.0 & 2 & M \\
\hline CM-3 & 08/21/97 & OC, Hawaii & 51.5 & 07/28/99 & DS, Hawaii & $-^{\mathrm{b}}$ & 0 & $\mathrm{U}$ \\
\hline CM-4 & $12 / 21 / 98$ & OC, Oahu & 69.4 & $12 / 10 / 99$ & DS, Oahu & 69.6 & 3 & $\mathrm{~F}$ \\
\hline CM-5 & 12/09/99 & LS-R, Oahu & 75.9 & $01 / 19 / 00$ & DS, Oahu & 76.4 & 3 & $\mathrm{~F}$ \\
\hline CM-6 & $10 / 05 / 99$ & OC, Hawaii & 55.9 & $05 / 09 / 00$ & DS, Hawaii & 56.3 & 0 & $\mathrm{~F}$ \\
\hline CM-7 & $01 / 06 / 00$ & OC, Oahu & 55.1 & $07 / 03 / 00$ & DS, Oahu & 56.3 & 0 & M \\
\hline CM-8 & $04 / 24 / 00$ & OC, Oahu & 70.6 & 02/20/01 & LS-Eu, Oahu & 70.0 & 0 & $\mathrm{U}$ \\
\hline CM-9 & $04 / 14 / 00$ & OC, Oahu & 44.7 & 04/23/01 & LS-Eu, Oahu & 44.5 & 3 & $\mathrm{M}$ \\
\hline CM-10 & $04 / 25 / 00$ & LS-R, Oahu & 83.8 & $12 / 11 / 01$ & LS-Eu, Oahu & 85.5 & 2 & $\mathrm{~F}$ \\
\hline CM-11 & 07/08/97 & OC, Oahu & 54.8 & 03/28/02 & DS, Oahu, & 57.2 & 2 & $\mathrm{M}$ \\
\hline CM-12 & 05/12/98 & OC, Oahu & 57.4 & 10/17/02 & LS-Eu, Oahu & 60.2 & 2 & $\mathrm{M}$ \\
\hline CM-13 & 06/17/94 & OC, Hawaii & 45.5 & $10 / 19 / 03$ & DS, Hawaii & 69.5 & 0 & $\mathrm{~F}$ \\
\hline CM-14 & 05/16/00 & OC, Oahu & 51.0 & 07/14/04 & DS, Oahu & 53.7 & 1 & $\mathrm{~F}$ \\
\hline
\end{tabular}


with half injected into each pectoral muscle. Before sea turtles were released into the wild, standard carapace measurements were taken and Inconel ${ }^{\mathrm{TM}}$ and passive integrated transponder (PIT) tags were applied (Balazs 1999, Balazs \& Chaloupka 2004). All of the sea turtles were eventually recovered by the stranding network, the flippers were collected and soft tissue was removed to expose both humeri.

Growth marks in bone are best differentiated using decalcified and stained thin-sections (Klevezal 1996, Goshe et al. 2009). Because decalcification removes the OTC mark, we prepared 2 sets of cross-sections from each humerus. These cross-sections were taken from one of the humeri from each sea turtle at a point just distal to the deltopectoral crest (Zug et al. 1986, Snover \& Hohn 2004) using a Buehler ${ }^{\circledR}$ isomet lowspeed saw. Three sequential sections were taken, a 2 to $3 \mathrm{~mm}$ thick section for processing and $<1 \mathrm{~mm} \mathrm{sec-}$ tions on either side of the thick section that were not further processed (i.e. not decalcified) to enable observation of OTC marks.

The sample location for bone cross-sections is consistent with recent successful studies identifying and validating growth layers in loggerhead and Kemp's ridley sea turtles (Snover \& Hohn 2004), but varied significantly from the only other attempt to validate growth marks in green sea turtles. In the study on live tetracycline-marked green sea turtles from the Bahamas, Bjorndal et al. (1998) collected biopsy samples from the distal region of the humerus, similar to a method successfully used with loggerhead sea turtles (Klinger \& Musick 1992). Previous studies of growth marks in humeri have identified the proximal end of the bone at the site of the deltopectoral muscle insertion scar to be best for identifying growth marks because it contains the most cortical bone, i.e. the region of bone in which the growth layers occur (Zug et al. 1986, Snover \& Hohn 2004). Also, because they were using live animals, Bjorndal et al. (1998) only sampled to the central trabecular area of the humerus rather than taking an entire cross-section in order to not sever the humerus. To test whether their inability to find growth marks was related to differences in sampling technique - including: (1) taking samples from the distal rather than the proximal end of the humerus (specifically midway between the narrowest part of the shaft and the epicondyles), and (2) the use of a partial section from the dorsal surface rather than complete cross-sections - we replicated their sampling technique by cutting a wedge of bone from the site they described from 5 of the sea turtles in our study. Our wedges were $8 \times 8 \times 5.2 \mathrm{~mm}$, approximately the same size as their biopsy samples (mean $=7.6 \times 7.5 \times 6.4 \mathrm{~mm})$. From this wedge, a thicker ( 2 to $3 \mathrm{~mm}$ ) section was cut for decalcification, thin-sectioning and staining and $1 \mathrm{~mm}$ sections were taken from each side of the thick section to identify the OTC mark.

The thicker cross-sections were prepared for skeletochronology analysis following the methods described in Snover \& Hohn (2004). Each section was fixed in $10 \%$ neutral buffered formalin (Fisher Scientific) and then decalcified using a commercial decalcifying agent (RDO, Apex Engineering Products). Time to decalcification varied with the size of the bone and the strength of the solution, usually between 24 and $36 \mathrm{~h}$. Following decalcification, $25 \mu \mathrm{m}$ cross-sections were made using a freezing-stage microtome. Sections were stained in Ehrlich's hematoxylin diluted 1:1 with distilled water (Klevezal 1996) and mounted on slides in $100 \%$ glycerin.

A stained thin-section from each humerus was compared with the 2 unprocessed sections. The relative amount of cortical bone changes quickly, resulting in adjacent sections potentially having significantly different appearances. To validate the deposition rate of skeletal growth marks using OTC marking, it was important to find a stained section and one of the unprocessed sections with the same identifiable landmarks to use as reference points. The thin-section with identifiable landmarks similar to those on the stained section was selected for this study. The OTC mark was observed using a compound microscope with a UV light source at 40 to $100 \times$ magnification, and the stained thin-section was observed with the same microscope using transmitted light. Regions at the perimeter of both the processed and unprocessed cross-sections were observed and matching regions were identified using corresponding landmarks; these regions were then photographed. At the corresponding sites, the distance from the edge of the bone to the OTC mark was measured and the distance was noted on the stained section. The number of LAGs between the OTC mark and the outer edge of the bone were counted without prior knowledge of the date of the OTC treatment. All samples were examined for presence and location of the OTC mark on separate occasions by M.L.S., A.A.H. and L.R.G. The number of LAGs present outside of the OTC mark were counted on separate occasions by M.L.S. and A.A.H., first individually and then jointly. L.R.G. provided input when there was no consensus between the counts by M.L.S. and A.A.H.

Following the enumeration of the LAGs, we estimated the expected number of LAGs given the time between treatment and death. In reptiles where the timing of the deposition of the LAGs has been identified, including Kemp's ridley sea turtles, LAGs are deposited during the winter or early spring (Castanet 1985, Waye \& Gregory 1998, Snover \& Hohn 2004). For lack of evidence to the contrary, we assumed the same would be true of the green sea turtles in the present study. 
Table 2. Chelonia mydas. Results of skeletochronology and oxytetracycline (OTC) mark observations for 10 green sea turtles from Hawaii where OTC marks were clearly visible. Recovery date indicates the date the animal was recovered as a dead stranding. Growth is the difference in notch-to-tip straight line carapace length measured at OTC treatment and again at recovery. Number of lines of arrested growth (LAGs) deposited after OTC injection and uptake in the bone tissue in full humerus cross-sections and in distal biopsies are noted. $\mathrm{n} / \mathrm{a}$ : not applicable (distal biopsy sections were not taken from these samples)

\begin{tabular}{|c|c|c|c|c|c|}
\hline \multirow[t]{2}{*}{ ID } & \multirow{2}{*}{$\begin{array}{l}\text { Time at } \\
\text { large (yr) }\end{array}$} & \multirow{2}{*}{$\begin{array}{l}\text { Growth } \\
\text { (cm) }\end{array}$} & \multirow[t]{2}{*}{ OTC mark visible } & \multicolumn{2}{|c|}{ LAGs outside OTC } \\
\hline & & & & Cross-section & Biopsy \\
\hline CM-1 & 1.80 & $3.4^{\mathrm{a}}$ & Yes & 1 & 1 \\
\hline CM-3 & 1.93 & ${ }_{-}^{\mathrm{b}}$ & Yes & 2 & 2 \\
\hline CM-4 & 0.97 & 0.2 & Yes; faint & 1 & $-^{c}$ \\
\hline CM-5 & 0.11 & 0.5 & Yes; faint; at edge & 0 & $-^{\mathrm{c}}$ \\
\hline CM-8 & 0.83 & -0.6 & Yes; faint, at edge & 0 & $\mathrm{n} / \mathrm{a}$ \\
\hline CM-9 & 0.83 & 0.3 & Yes; faint, at edge & 0 & $\mathrm{n} / \mathrm{a}$ \\
\hline CM-11 & 4.72 & 2.4 & Yes & 4 & $\mathrm{n} / \mathrm{a}$ \\
\hline CM-12 & 4.44 & 2.8 & Yes & 4 & $\mathrm{n} / \mathrm{a}$ \\
\hline CM-13 & 9.35 & 12.2 & Yes & 9 & $\mathrm{n} / \mathrm{a}$ \\
\hline CM-14 & 4.16 & 2.7 & Yes & $\begin{array}{c}4 \text { (3 double, } \\
1 \text { single) }\end{array}$ & $\mathrm{n} / \mathrm{a}$ \\
\hline \multicolumn{6}{|c|}{$\begin{array}{l}\text { a Carapace length at stranding not available. Sea turtle was captured and } \\
\text { measured } 3 \text { mo prior to death and this measurement was used as a proxy for } \\
\text { final measurement and growth }\end{array}$} \\
\hline
\end{tabular}

\section{RESULTS}

The OTC marks were visible in 10 of the 14 humeri (Table 2). In 7 of those 10, there was additional bone growth beyond the OTC mark that was useful for validation of growth mark deposition rate, whereas in the other 3 bones there was no bone growth visible beyond the OTC mark (i.e. the OTC mark was at the outer edge of the bone; Table 2).

Sample CM-1 was recovered during February, 1.8 yr after treatment with OTC (Tables 1 \& 2). On the humerus cross-section, we observed one LAG external to (i.e. deposited after) a distinct OTC, and one LAG visible just internal to (i.e. deposited prior to) the OTC mark (Fig. 1a,b). The LAG just prior to the OTC mark was likely deposited in winter/spring 1997 and the one external to the OTC mark would have been deposited in winter/spring 1998. Similar results were found for the distal biopsy section, with one LAG visible outside of the OTC mark (Fig. 2a,b).

Sample CM-3 was recovered during July, 1.94 yr after treatment (Tables 1 \& 2). On the humerus crosssection, we observed 2 LAGs external to the OTC mark (Fig. 1c,d). These LAGs likely represent the winter/ spring 1998 and winter/spring 1999 LAGs. Similar results were found with the humerus distal biopsy. Two LAGs were visible outside of the OTC mark (Fig. 2c,d).

The OTC mark on the cross-section of CM-4 was fainter than in the other samples but was visible around the circumference of the bone section. This specimen was treated in December 1998 and recovered in December 1999 (Tables 1 \& 2). One LAG was deposited between the OTC mark and the outer edge of the bone in the cross-section (Fig. 1e,f). The OTC mark could not be detected in the biopsy section (Fig. 2e,f).

Sample CM-11 was recovered in March 2002 and treated with OTC in July 1997. Assuming that the LAG for 1997 had already been deposited prior to treatment with OTC, the sea turtle was at large for 4 springs - 1998, 1999, 2000 and 2001 - and 4 LAGs were observed outside of the OTC mark (Table 2, Fig. 1g,h). Similarly, CM-12 was treated in May 1998 and recovered in October 2002. Assuming that the 1998 LAG was already deposited prior to OTC treatment, our results indicated that the sea turtle was at large for 4 springs: 1999, 2000, 2001 and 2002 (Table 2, Fig. 1i,j).

The sea turtle with the longest time at large between treatment and recovery was CM-13. This sea turtle was treated in June 1994 and recovered in October 2003; hence if growth marks are annual there should be 9 LAGs representing spring seasons 1995 to 2003, and this was supported by the results (Table 2, Fig. 1k,l). This sea turtle was captured and measured multiple times while it was at large. After OTC treatment, it was next captured on 27 October 1997, measuring $57.3 \mathrm{~cm} \mathrm{SCL}$, an increase of $11.8 \mathrm{~cm}$. Balazs \& Chaloupka (2004) estimate annual growth rates for this population to range from 0 to $2.5 \mathrm{~cm} \mathrm{yr}^{-1}$, making this amount of growth remarkable. Although it cannot be determined when the growth occurred from the capture records, examination of the bone suggests that most of that growth was confined to the year following OTC treatment, given the wide spacing of the LAGs (Fig. 11). Also visible between LAGs 8 and 9 (Fig. 11) are numerous lamellae, which in partial cross-sections can be confused for LAGs (Bruce et al. 2002), highlighting the need for full crosssections to correctly identify bone features.

In CM-14 we observed one mark just interior to the OTC mark, likely deposited in spring of 2000 prior to OTC treatment. In our first read of this bone, we observed 7 LAGs. In reexamining this LAG after noting the duration of time it was at large, $4.16 \mathrm{yr}$, we observed that there were 3 pairs of closely spaced double LAGs. If these double LAGs are considered to be representative of a single mark (Castanet et al. 1993, Snover \& Hohn 2004, Goshe et al. 2010), then there were 4 annual marks after the OTC mark, which corre- 

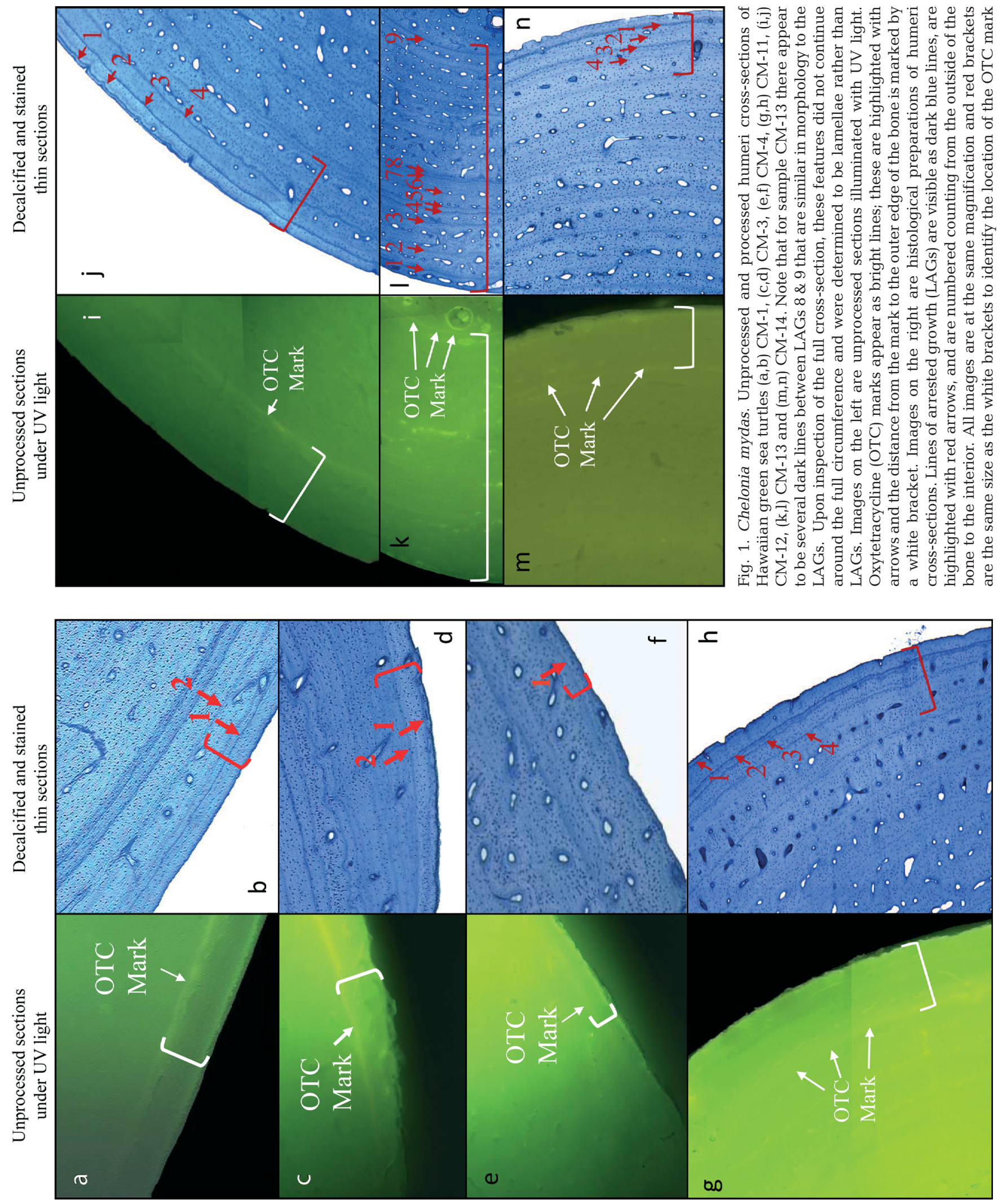
Unprocessed sections under UV light

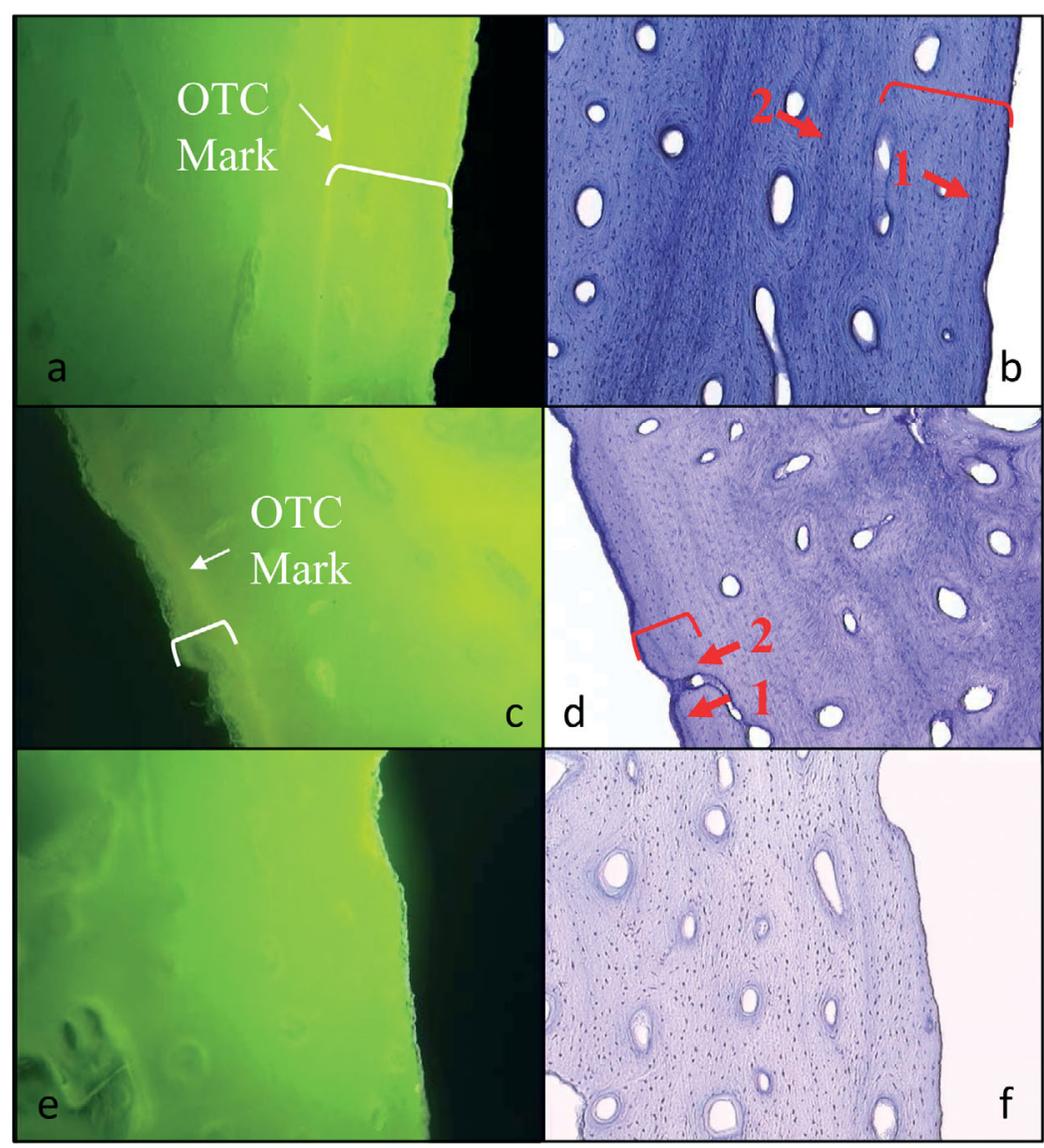

Fig. 2. Chelonia mydas. Unprocessed and processed distal biopsy sections of humeri from Hawaiian green sea turtles $(\mathrm{a}, \mathrm{b}) \mathrm{CM}-1,(\mathrm{c}, \mathrm{d}) \mathrm{CM}-3$ and $(\mathrm{e}, \mathrm{f}) \mathrm{CM}-4$. Details as for Fig. 1. Note that the OTC mark is not visible in panel e

with annual deposition. Time-at-large for these 6 turtles ranged from 1 to $9 \mathrm{yr}$. The seventh turtle also provided evidence of annual mark deposition and, because it was OTC marked, it allowed confidence in the interpretation of double LAGs as annual marks.

It is unclear why no fluorescent marks were observed in 3 of the turtles. Each was at large for less than $1 \mathrm{yr}$ after OTC injection and this may not have been enough time to be able to discern the OTC mark from the autofluorescence at the outer edge of the humerus. In a study of wild loggerheads, Klinger \& Musick (1992) did not find OTC marks in 5 of 14 samples. All 5 biopsies were from sea turtles that had been at large after treatment for $1 \mathrm{yr}$; the 3 biopsies taken 2 or 3 yr posttreatment all contained visible OTC marks. Frazier (1985) found clearly fluorescent lines after $265 \mathrm{~d}$ in 5 of 6 captive green sea turtles. The sixth sea turtle died on the 139th day of the study and no OTC mark was visible. Bjorndal et al. (1998) observed OTC marks in all 25 biopsies taken from green sea turtles in their study. However, they did not observe LAGs in any of the 25 stained biopsy thin-sections and therefore could not validate annual growth mark deposition. In the present study we were able to detect OTC marks in all but one of the sea turtles that were at large for $\geq 0.97 \mathrm{yr}$. The exception,

sponded with the number of years the sea turtle was at large (Table 2, Fig. 1m,n). These annual marks would correspond with the years 2001, 2002, 2003 and 2004.

For the other 7 sea turtles, either no OTC marks were observed in humeri or the mark was too near the outer edge of the cross-section to detect LAGs. Four of these turtles were at large for much less than $1 \mathrm{yr}$; the other 3 were at large for more than 1 yr but experienced little or no growth (Tables $1 \& 2$ ).

\section{DISCUSSION}

The results of this study present evidence that skeletal growth marks are generally deposited on an annual basis in this population of green sea turtles. For the 7 sea turtles that had fluorescent marks and bone growth outside of the OTC mark, 6 had the number of LAGs outside of the fluorescent marks that was consistent
CM-10, was at large for $1.63 \mathrm{yr}$ and grew $1.7 \mathrm{~cm}$. It is unclear why we could not detect an OTC mark in this sea turtle.

Snover \& Hohn (2004) noted that one benefit of validation studies for skeletochronology is to provide the opportunity to identify anomalous LAGs, marks in bone cross-sections similar in appearance to LAGs but not representing annual marks. These marks have been observed in other sea turtles, as well as other species of amphibians (see Snover \& Hohn 2004), and can confound age estimates. Snover \& Hohn (2004) noted an anomalous mark in a loggerhead sea turtle that had been raised in captivity and released into the wild. The anomalous mark corresponded to when the animal was released into the wild, and they suggested the mark was a result of stress. In applying skeletochronology to northwest Atlantic green sea turtles, Goshe et al. (2010) interpreted closely spaced double LAGs as representing a single year. The results from CM-14 sup- 
port this interpretation, although it is unclear why double LAGs would be deposited.

Sample CM-14 came from a sea turtle that was initially captured and finally recovered in Hanauma Bay on $\mathrm{Oahu}_{\text {; }}$ hence it was likely a resident of the bay, as juvenile green sea turtles in Hawaii appear to have a strong site fidelity to foraging grounds (Balazs \& Chaloupka 2004). Hanauma Bay is a marine life conservation district in the state of Hawaii that, although closed to any fishing activity, is a major tourist destination, seeing over 2000 visitors each day with the primary activity of snorkeling. This is likely a very stressful environment for a sea turtle and could have been a factor in the anomalous appearance of the marks observed in the humerus.

A significant amount of effort has been expended to find the optimal histological method for elucidating LAGs and detecting anomalous marks (Snover \& Hohn 2004, Goshe et al. 2009). One of the outcomes of this effort is that LAGs differentiate better in relatively thick stained sections. Bjorndal et al. (1998) stained sections $4 \mu \mathrm{m}$ thick. In contrast, the sections in the present study were $25 \mu \mathrm{m}$ thick, a thickness successfully used for validating annual growth marks in loggerheads and Kemp's ridleys (Snover \& Hohn 2004). Each of the distal biopsy sections showed a greater relative amount of cancellous to cortical bone, or the type of bone in which growth marks are lost to bone remodeling. We found that LAGs in the distal biopsy sections were more diffuse and, therefore, less obvious than LAGs in the proximal cross-sections. We suggest that these characteristics may result in less perceptible LAGs in distal sections. Any such increased difficulty in correctly identifying LAGs would be further compounded in a biopsy section because LAGs are not uniformly visible around the circumference of the section. Use of the proximal humerus, i.e. distal to the deltopectoral crest, has been well established as the optimal location for identifying growth marks in Cheloniidae, as have the limitations of not using complete cross-sections of bone for counting LAGs (Zug et al. 1986, Snover \& Hohn 2004). In spite of these limitations, we did find a good correspondence of LAG counts between the full cross-sections and the biopsies. However, although sampling bone for skeletochronology from live turtles may be valuable under certain circumstances, small, partial bone sections obtained from biopsies are still likely to result in higher error rates in age estimates because of the difficulties in correctly identifying LAGs, as described above.

Bjorndal et al. (1998) suggest that their results indicate a lack of growth marks in tropical sea turtles because environmental conditions allow for continuous growth. Previous studies of tropical sea turtles (Zug \& Glor 1998, Zug et al. 2002) and other tropical reptiles (Patnaik \& Behera 1981, Chinsamy et al. 1995, De Buffrenil \& Castenet 2000) have shown growth marks. It is possible that green sea turtles in the southern Bahamas do not exhibit annual growth marks because of an acyclic growth environment that is different from other equatorial areas; however, the observation of growth marks in the Hawaiian and other equatorial green sea turtle populations suggests that sample processing and/or use of distal humeral biopsies are another potential reason that growth marks were not observed by Bjorndal et al. (1998).

The present study not only confirms the existence of LAGs in green sea turtles in Hawaii, but also validates that they are annual, as has been found for growth marks in loggerheads and Kemp's ridleys (Klinger \& Musick 1992, Coles et al. 2001, Snover \& Hohn 2004). It further provides support for additional OTC marking, which appears to be a successful technique for sea turtles that are growing, even with one dose, possibly because of the pharmacokinetics of OTC in turtles which results in a long elimination time (Harms et al. 2004). Additional OTC marking will help identify anomalous LAGS, provide a larger sample size for validation and allow comparisons among populations.

Acknowledgments. We are especially grateful to S. K. K. Murakawa and M. Rice for their assistance in the field and with necropsies and sample recovery. We thank R. Humphreys, S. Kubis and S. K. K. Murakawa for comments on earlier versions of this manuscript. This work complied with all animal experimentation and ethics standards of the USA. Reference to trade names does not imply endorsement by the authors or their institutions.

\section{LITERATURE CITED}

Balazs GH (1999) Factors to consider in the tagging of sea turtles. In: Eckert KL, Bjorndal KA, Abreu-Grobois FA, Donnelly $M$ (eds) Research and management techniques for the conservation of sea turtles. IUCN/SSC Marine Turtle Specialist Group Publication No. 4, Washington, D.C., p 101-109

Balazs GH, Chaloupka M (2004) Spatial and temporal variability in somatic growth of green sea turtles (Chelonia mydas) resident in the Hawaiian archipelago. Mar Biol 145:1043-1059

Bjorndal KA, Bolten AB, Bennet RA, Jacobson ER, Wronski TJ, Valeski JJ, Eliazar PJ (1998) Age and growth in sea turtles: limitations of skeletochronology for demographic studies. Copeia 1998:23-30

Bruce RC, Castanet J, Francillon-Vieillot H (2002) Skeletochronological analysis of variation in age structure, body size, and life history in three species of Desmognathine salamanders. Herpetologica 58:181-193

Castanet J (1985) La squeletochronologie chez les reptiles. I. Resultats experimentaux sur la signification des marques de croissance squelettiques chez les lezards at les tortues. Ann Sci Nat B 13:23-40

Castanet J, Francillon-Vieillot H, Meunier FJ, De Ricqles A (1993) Bone and individual aging. In: Hall BBK (ed) Bone, 
Vol. 7: Bone Growth B. CRC Press, Boca Raton, FL, p 245-283

Chaloupka M, Work TM, Balazs GH, Murakawa SKK, Morris $\mathrm{T}$ (2008) Cause-specific temporal and spatial trends in green turtle strandings in the Hawaiian Archipelago. Mar Biol 154:887-898

Chinsamy A, Hanrahan SA, Neta RM, Seely M (1995) Skeletochronological assessment of age in Angolosaurus skoogi, a cordylid lizard living in an aseasonal environment. J Herpetol 29:457-460

Coles WC, Musick JA, Williamson LA (2001) Skeletochronology validation from an adult loggerhead (Caretta caretta). Copeia 2001:240-242

De Buffrenil V, Castenet J (2000) Age estimation by skeletochronology in the Nile monitor (Varanus niloticus), a highly exploited species. J Herpetol 34:414-424

Frazier J (1985) Tetracycline as an in vivo label in bones of green turtles Chelonia mydas (L.). Herpetologica 41: 228-234

Goshe LR, Avens L, Bybee J, Hohn AA (2009) An evaluation of histological techniques used in skeletochronological age estimation of sea turtles. Chelonian Conserv Biol 8:217-222

Goshe LR, Avens L, Scharf FS, Southwood AL (2010) Estimation of age at maturation and growth of Atlantic green turtles (Chelonia mydas) using skeletochronology. Mar Biol 157:1725-1740

Harms CA, Papich MG, Stamper MA, Ross PM, Rodriguez MX, Hohn AA (2004) Pharmacokinetics of oxytetracycline in loggerhead sea turtles (Caretta caretta) after single intravenous and intramuscular injections. J Zoo Wildl Med 35:477-488

Klevezal GA (1996) Recording structures of mammals: deter-

Editorial responsibility: Hans Heinrich Janssen, Oldendorf/Luhe, Germany mination of age and reconstruction of life history. A. A. Balkema, Rotterdam

Klinger RC, Musick JA (1992) Annular growth layers in juvenile loggerhead turtles (Caretta caretta). Bull Mar Sci 51: 224-230

Kottek M, Grieser J, Beck C, Rudolf B, Rubel F (2006) World map of Köppen-Geiger climate classification updated. Meteorol Z 15:259-263

Milch RA, Rall DP, Tobie JE (1958) Fluorescence of tetracycline antibiotics in bone. J Bone Joint Surg 40A:897-910

Patnaik BK, Behera HN (1981) Age-determination in the tropical agamid garden lizard, Calotes versicolor (Daudin), based on bone histology. Exp Gerontol 16:295-307

Snover ML, Hohn AA (2004) Validation and interpretation of annual skeletal marks in loggerhead (Caretta caretta) and Kemp's ridley (Lepidochelys kempi) sea turtles. Fish Bull 102:682-692

> Waye HL, Gregory PT (1998) Determining the age of garter snakes (Thamnophis spp.) by means of skeletochronology. Can J Zool 76:288-294

Zug GR, Glor RE (1998) Estimates of age and growth in a population of green sea turtles (Chelonia mydas) from the Indian River lagoon system, Florida: a skeletochronological analysis. Can J Zool 76:1497-1506

Zug GR, Wynn AH, Ruckdeschel C (1986) Age determination of loggerhead sea turtles, Caretta caretta, by incremental growth marks in the skeleton. Smithson Contrib Zool 427. Smithsonian Institution Press, Washington, DC

Zug GR, Balazs GH, Wetherall JA, Parker DM, Murakawa SKK (2002) Age and growth of Hawaiian green sea turtles (Chelonia mydas): an analysis based on skeletochronology. Fish Bull 100:117-127

Submitted: October 27, 2010; Accepted: March 16, 2011

Proofs received from author(s): April 29, 2011 